\title{
Subclinical diabetic neuropathy: similarities between electro- physiological results of patients with Type 1 (insulin-dependent) and Type 2 (non-insulin-dependent) diabetes mellitus
}

\author{
P.H.Hendriksen ${ }^{1}$, P. L. Oey ${ }^{1}$, G.H. Wieneke ${ }^{1}$, B. Bravenboer ${ }^{2}$ and J.D. Banga ${ }^{2}$ \\ ${ }^{1}$ Department of Clinical Neurophysiology and ${ }^{2}$ Department of Internal Medicine, University Hospital, Utrecht, The Netherlands
}

Summary. Type 1 (insulin-dependent) and Type 2 (non-insulin-dependent) diabetic patients share many clinical and biochemical characteristics. However, sural nerve biopsies from patients with advanced and chronic neuropathy show ultrastructural differences between these two groups. We investigated whether at a subclinical stage of the illness, when Type 1 and Type 2 diabetic patients are clinically uniform and the histopathological nerve alterations are not advanced, comparison between the two diabetes groups might show differences in nerve fibre involvement related to the different pathogeneses of the neuropathies. A total of 88 diabetic patients (52 Type 1 and 36 Type 2), with a subclinical form of polyneuropathy were selected. The clinical neurophysiological examination consisted of motor and sensory nerve conduction studies, Hoffmann (H)-reflex, single fibre electromyography and static as well as dynamic pupillometry. With regard to clinical neurophysiological abnormalities, the se- verity of the polyneuropathy appeared to be equal in both groups. Despite the absence of clinical symptoms the neurophysiological abnormalities were pronounced and it was impossible to differentiate Type 1 diabetic patients from Type 2 diabetic patients on a clinical neurophysiology basis when correcting for differences in age, height, and duration of illness. In the Type 1 diabetic group as well as in the Type 2 diabetic group the autonomic nerve fibres and nerves in the legs were more frequently affected than the thick myelinated nerves in the arms. These findings do not support the assumption that there is a difference in the manifestation of polyneuropathy between Type 1 and Type 2 diabetic patients.

Key words: Diabetic neuropathy, Type 1 (insulin-dependent) diabetes mellitus, Type 2 (non-insulin-dependent) diabetes mellitus, comparative study.
Of the diabetic neuropathies, peripheral symmetrically mixed sensory-motor-autonomic neuropathy is the most common form [1], which is associated with both Type 1 (insulin-dependent) and Type 2 (non-insulin-dependent) diabetes mellitus [1]. In both types of diabetes, morphological nerve lesions occur at an advanced stage of the disease [2-5]. Sima et al. [6] have stated that the histopathology is modified by the type of diabetes. They compared morphometric data from sural biopsies obtained from both Type 1 and Type 2 diabetic patients. The degrees of nerve fibre loss and demyelination were in the same range. In the nerves of the Type 2 diabetic patients however, no axonal atrophy was found. This structural discordance is thought to be the result of differences in the pathogenesis of the neuropathy [7].

It should be emphasized that these lesions have only been described in advanced chronic neuropathy. Little is known about possible differences in fibre type related nerve involvement in the early stages of Type 1 and Type 2 diabetic polyneuropathy when patients have no symp- toms of neuropathy. More knowledge about functional abnormalities in the two entities at a subclinical stage of the illness might provide more insight into differences in the aetiology and pathogenesis of diabetic neuropathy. However, a comparative study involving Type 1 and Type 2 diabetic patients has some pitfalls; when patients are classified as Type 1 or Type 2 diabetic, one is nearly always confronted with the differences between these groups concerning age and duration of illness. Type 1 diabetic patients are in general younger with a long duration of illness, while Type 2 diabetic patients are older with a shorter, or more difficult to assess, duration of illness [8].

We carried out extensive clinical neurophysiological examinations of Type 1 and Type 2 diabetic patients with a subclinical form of neuropathy in order to assess the functions of different types of nerve fibres, small unmyelinated fibres as well as large myelinated nerve fibres [9]. The examination of motor and sensory conduction studies of arms and legs is considered to provide measurements of 
Table 1. Characteristics of Type 1 (insulin-dependent) and Type 2 (non-insulin-dependent) diabetic patients studied

\begin{tabular}{|c|c|c|c|}
\hline & \multicolumn{3}{|c|}{ Diabetic patients } \\
\hline & Type 1 & Type 2 & $\begin{array}{l}\text { Significance } \\
\text { of difference }\end{array}$ \\
\hline Number $(n)$ & 52 & 36 & \\
\hline Age (years) & $46.3 \pm 11.5$ & $61.1 \pm 7.7$ & $p<0.05^{\mathrm{a}}$ \\
\hline $\begin{array}{l}\text { Duration of diabetes } \\
\text { (years) }\end{array}$ & $24.6 \pm 10.5$ & $10.0 \pm 7.3$ & $p<0.05^{\mathrm{a}}$ \\
\hline Body height $(\mathrm{cm})$ & $174.1 \pm 10.3$ & $173.6 \pm 8.9$ & $\mathrm{NS}^{\mathrm{a}}$ \\
\hline Sex ratio (male:female) & $33: 19$ & $20: 16$ & $N^{b}$ \\
\hline
\end{tabular}

${ }^{\mathrm{a}} t$-test; ${ }^{\mathrm{b}}$ chi-square test

Age, duration of diabetes, height are given as means \pm SD

Table 2. Test results of the clinical neurophysiological examinations ${ }^{a}$

\begin{tabular}{|c|c|c|c|c|}
\hline & \multicolumn{4}{|c|}{ Diabetic patients } \\
\hline & \multicolumn{2}{|c|}{$\begin{array}{l}\text { Type } 1 \\
\text { (insulin- } \\
\text { dependent) }\end{array}$} & \multicolumn{2}{|c|}{$\begin{array}{l}\text { Type } 2 \\
\text { (non-insulin- } \\
\text { dependent) }\end{array}$} \\
\hline Test & $n$ & & $n$ & \\
\hline Tibial nerve (MNCV, m/s) & 45 & $33.9 \pm 7.7$ & & $32.8 \pm 18.8$ \\
\hline H-reflex (Soleus muscle, ms) ${ }^{\mathrm{b}}$ & 40 & $32.0 \pm 15.0$ & 25 & $31.8 \pm 13.8$ \\
\hline Pupil diameter percentage $(\%)^{c}$ & & $44.1 \pm 8.7$ & & $47.0 \pm 7.3$ \\
\hline Pupil constriction latency $(\mathrm{ms})^{c}$ & & $242.7 \pm 32$ & 31 & $244.5 \pm 31$ \\
\hline Sural nerve (SNCV, m/s) & 43 & $36.4 \pm 9.6$ & 25 & $35.1 \pm 14.2$ \\
\hline SFEMG (mean jitter, $\mu s)$ & 51 & $71.0 \pm 16.2$ & 35 & $69.1 \pm 15.9$ \\
\hline SFEMG (fibre density) ${ }^{c}$ & 51 & $2.96 \pm 1.8$ & 35 & $2.91 \pm 2.0$ \\
\hline Ulnar nerve (SNCV, m/s) & 51 & $43.0 \pm 15.3$ & 33 & $42.2 \pm 17.9$ \\
\hline Ulnar nerve (MNCV, $\mathrm{m} / \mathrm{s})$ & 52 & $53.5 \pm 5.6$ & 36 & $52.4 \pm 6.6$ \\
\hline
\end{tabular}

${ }^{a}$ Mean values \pm SD of the basically recorded data of patients where a response was obtainable; ' Value is dependent on age and body height; ${ }^{\circ}$ Value is dependent on age.

$n$, Number of patients where a test response was obtainable; MNCV, Motor nerve conduction velocity; SNCV, sensory nerve conduction velocity; Hoffmann $(\mathrm{H})$-reflex, latency $\mathrm{H}$-reflex minus latency $\mathrm{M}$-response; SFEMG, single fibre electromyography

Table 3. Percentage of Type 1 (insulin-dependent) and Type 2 (noninsulin-dependent) diabetic patients tested with abnormal results

\begin{tabular}{|c|c|c|c|}
\hline & \multirow{2}{*}{$\begin{array}{l}\text { Control } \\
\text { value }\end{array}$} & \multicolumn{2}{|c|}{ Diabetic patients } \\
\hline & & Type 1 & Type 2 \\
\hline Test & & $\mathrm{n}=52$ & $n=36$ \\
\hline Tibial nerve (MNCV) & $>35.4 \mathrm{~m} / \mathrm{s}$ & $71 \%(11 \%)$ & $81 \%(8 \%)$ \\
\hline H-reflex (Soleus muscle) & $<31.2 \mathrm{~ms}$ & $71 \%(28 \%)$ & $69 \%(26 \%)$ \\
\hline Pupil constriction latency & $<220 \mathrm{~ms}$ & $67 \%(0 \%)$ & $69 \%(0 \%)$ \\
\hline Pupil diameter percentage & $<46.5 \%$ & $62 \%(0 \%)$ & $65 \%(0 \%)$ \\
\hline Sural nerve (SNCV) & $>38.7 \mathrm{~m} / \mathrm{s}$ & $56 \%(38 \%)$ & $64 \%(43 \%)$ \\
\hline SFEMG (mean jitter) ${ }^{a}$ & $<60.0 \mu \mathrm{s}$ & $58 \%(0 \%)$ & $31 \%(0 \%)$ \\
\hline SFEMG (fibre density) ${ }^{\mathrm{a}}$ & $<2.22$ & $46 \%(0 \%)$ & $19 \%(0 \%)$ \\
\hline Ulnar nerve (SNCV) & $>42.9 \mathrm{~m} / \mathrm{s}$ & $40 \%(8 \%)$ & $33 \%(6 \%)$ \\
\hline Ulnar nerve (MNCV) & $>46.3 \mathrm{~m} / \mathrm{s}$ & $31 \%(0 \%)$ & $19 \%(0 \%)$ \\
\hline
\end{tabular}

${ }^{\mathrm{a}} p<0.05$.

As normal limit the mean \pm 2 SD were used.

$\%$ within parentheses, percentage of patients where no response could be obtained is given.

MNCV, Motor nerve conduction velocity; SNCV, sensory nerve conduction velocity; Hoffmann (H)-reflex, latency $\mathbf{H}$-reflex minus latency M-response; SFEMG, single fibre electromyography thick myelinated and distal parts of the nerves [10]. The Hoffman (H)-reflex of the soleus muscle is thought to be valuable in detecting proximal nerve segment abnormalities [11]. Single fibre electromyography (SFEMG) gives information about the microphysiology of the motor unit and is useful to quantify the function of the terminal nerve branches and motor endplates [12]. The measurements reflect the variability in the neuromuscular transmission time in motor endplates. Imperfect neuromuscular transmission at affected or immature neuromuscular junctions results in abnormal test results. Small myelinated and unmyelinated autonomic nerves can be examined with static and dynamic pupillometry [13].

The aim of the present study was to assess early peripheral nerve dysfunction using these clinical neurophysiological methods in a selected group of diabetic patients with asymptomatic polyneuropathy and to explore the possibility of making a diagnosis of Type 1 or Type 2 diabetes on the basis of the selective involvement of particular nerve fibre types.

\section{Subjects and methods}

\section{Patients}

A total of 88 diabetic patients were investigated, divided into two groups (52 Type 1 and 36 Type 2 ). They were selected after a routine hospital visit to the Department of Internal Medicine. All the Type 1 patients were insulin-dependent, as assessed by an increase in $\mathrm{C}$ peptide of less than $0.30 \mathrm{nmol} / \mathrm{l}$ at $6 \mathrm{~min}$ after $1 \mathrm{mg}$ glucagon i.v. The 52 Type 1 diabetic patients ( 33 male, 19 female) had a median age of 46.3 years and a mean diabetes duration of 24.6 years. The 36 Type 2 diabetic patients ( 20 male, 16 female) had a median age of 61.1 years and a mean duration of diabetes of 10.0 years (Table 1). Informed consent was obtained from all participants in the study, which was performed in accordance with the principles of the Declaration of Helsinki.

All patients were selected on the basis of a subclinical form of neuropathy (stage 1) according the criteria of Dyck et al. [9]. They showed no evidence of clinical neuropathy when evaluated with the Neuropathy Symptom Score and Neurologic Disability Score [9]. However, the patients all had an abnormal vibratory perception threshold or an abnormal thermal discrimination threshold as a positive sign of polyneuropathy or both. Vibration perception threshold was measured at the dorsum of the hand using an electromagnetic vibrameter, type III (Somedic AB, Stockholm, Sweden). Thermal discrimination threshold was measured at the forearm according the Peltier Principle (Medelec Triple-T, Old Woking, Surrey, UK). Results above the $P_{95}$-value (age-matched) for normal individuals were considered abnormal [14].

\section{Methods}

The examination consisted of motor and sensory nerve conduction studies, H-reflex measurement, SFEMG, static and dynamic pupillometry.

The nerve conduction studies were performed with standard surface stimulating and recording techniques (Viking apparatus, Nicolet, Madison, Wis., USA) on the left sural sensory nerve, the left posterior tibial motor nerve and the right ulnar motor and sensory nerve. The mean values $\pm S D$ of the basically recorded data are shown in Table 2 . The degree of abnormality was expressed by the deviation from the normal mean divided by the SD, using our laboratory data and published data as normal values [15] (Table 3). The 
Table 4. Results of univariate and multivariate analyses of variance of the differences between the test results of Type 1 (insulin-dependent) and Type 2 (non-insulin-dependent) diabetic patients (Type 1 and Type 2) with age, height and duration of illness as covariates (regression column)

\begin{tabular}{|c|c|c|c|c|c|c|}
\hline & \multicolumn{3}{|c|}{ Regression } & \multicolumn{3}{|c|}{$\begin{array}{l}\text { Type } 1 \text { and Type } 2 \\
\text { diabetes }\end{array}$} \\
\hline & $\mathrm{df}$ & $\mathrm{F}$ & $p$ & df & $\mathbf{F}$ & $p$ \\
\hline \multicolumn{7}{|c|}{ Nerve conduction velocity } \\
\hline $\begin{array}{l}\text { Ulnar nerve } \\
\text { (MNCV) } \\
\text { Tibial nerve }\end{array}$ & $3 ; 81$ & 5.210 & $<0.003$ & $1 ; 81$ & 0.140 & NS \\
\hline $\begin{array}{l}\text { (MNCV) } \\
\text { Ulnar nerve }\end{array}$ & $3 ; 65$ & 7.827 & $<0.001$ & $1 ; 65$ & 1.180 & NS \\
\hline (SNCV) & $3 ; 67$ & 4.796 & $<0.004$ & $1 ; 67$ & 0.012 & NS \\
\hline \multicolumn{7}{|c|}{ Single fibre electromyography } \\
\hline Fibre density & $3 ; 79$ & 10.126 & $<0.001$ & $1 ; 79$ & 1.216 & NS \\
\hline Mean jitter & $3 ; 77$ & 13.886 & $<0.001$ & $1 ; 77$ & 0.915 & NS \\
\hline \multicolumn{7}{|l|}{ Pupillometry } \\
\hline LC & $3 ; 69$ & 1.152 & NS & $1 ; 69$ & 0.032 & NS \\
\hline PD\% & $3 ; 78$ & 3.565 & $<0.018$ & $1 ; 78$ & 0.438 & NS \\
\hline Multivariate & $21 ; 161$ & $\begin{array}{l}\mathrm{T}^{2}=0.999 \\
\mathrm{~F}_{\text {approx }}= \\
2.553\end{array}$ & 0.001 & $7 ; 55$ & $\begin{array}{l}\mathrm{T}^{2}=0.053 \\
\mathrm{~F}_{\text {approx }}= \\
0.4147\end{array}$ & \\
\hline
\end{tabular}

MNCV, Motor nerve conduction velocity; SNCV, sensory nerve conduction velocity; LC, latency of pupil constriction; $\mathrm{PD} \%$, pupil/iris diameter percentage; $\mathrm{df}$, degree of freedom; $F$, the ratio of the mean square for regression to the mean square for the residual; $p$, twotailed significance level; $\mathrm{T}^{2}$, Hotelling's $\mathrm{T}^{2}$, (multivariate equivalent of $t$-value)

H-reflex of the soleus muscle was evoked by transcutaneous bipolar electric stimulation of the tibial nerve in the popliteal fossa. For normal data, H-reflex latencies ( $\mathrm{H}-\mathrm{M}$ interval) in relation to age and height as published by Visser et al. [16] were used. To minimize the effects of temperature, the limbs were warmed in warm water baths at $34^{\circ} \mathrm{C}$ for $30 \mathrm{~min}$ before the test, and kept at a temperature of $34^{\circ} \mathrm{C}$ with an infra-red heat lamp during the examination.

Single fibre electromyography of the anterior tibial muscle was performed (Counterpoint, Dantec apparatus, Skovlunde, Denmark) by inserting the electrode into the weakly contracting muscle as described by Trontelj and Stålberg [17]. With this technique, two measurements can be obtained: fibre density and jitter measurement. Fibre density is an index of the number of muscle fibres belonging to a single nerve fibre. Fibre density is increased in neurogenic disorders characterized by axonal degeneration with reinnervation [17]. The mean fibre density was calculated for 20 sampled recording potentials, and was considered abnormal if the mean value exceeded 2.22 (Table 3 ). Jitter measurement reflects the variability of interdischarge intervals between two muscle fibres belonging to the same motor unit. The jitter may increase during the denervation phase, before reinnervation begins $[12,18]$. Mean neuromuscular jitter is expressed as the mean consecutive difference (MCD) from 20 pairs of potentials. The upper limit of normal of the MCD for a pair of potentials was set at $60 \mu \mathrm{s}$. The results were considered abnormal if the jitter in more than $10 \%$ of the fibre pairs exceeded the normal single-pair limits or if the mean averaged MCD (MJ) of all pairs exceeded $55 \mu \mathrm{s}$.

Both static and dynamic pupillometry were performed in darkness. Static pupillometry consisted of measurement of the pupil diameter after 2 and 4 min of dark adaptation using infra-red photography. From the photographs the pupil diameter was determined in relation to the horizontal iris diameter and expressed as pupil diameter percentage (PD\%) [19]. For dynamic pupillometry, the infra-red light reflex technique was used [20]. With infra-red lightemitting diodes and sensors mounted on a frame fixed in front of both eyes, variations in pupil size can be recorded after a light stimulus in front of the right eye. The block-shaped stimulus had an intensity of 3.7 Log Troland (Troland = retinal illuminance) and a duration of $1.2 \mathrm{~s}$ every $5 \mathrm{~s}$. The latency between the onset of the stimulus and the start of the constriction was quantified by using the first deflection in the differentiated signal as the starting point of the constriction [21]. The latency of pupillary constriction was measured from at least ten artefact-free responses for both eyes. Age-related data \pm 2 SD in control subjects as published by Smith and Dewhurst [19] and Lanting et al. [22] were used as control data.

\section{Statistical analysis}

The analysis consisted of three parts. Firstly, the degree of clinical neurophysiological abnormality in both groups was compared, unadjusted for differences in age, height, and duration of illness. The psychophysical examinations (determination of vibratory perception threshold and temperature threshold for cold and heat stimuli) were used as selection criteria, yielding an overall abnormality of $100 \%$, and therefore excluded for group comparison analysis.

Secondly, the values of the variables in the two groups were compared when group differences concerning age, height, and duration of illness were taken into account. By means of linear regression analysis the relationship between the variables and age, height, and duration of illness was studied. An analysis of variance (univariate/multivariate) was used, with age, height, and duration of illness as covariates in order to test the difference between the two diabetic groups. For some variables this procedure could not be applied due to the large number of patients in which no response could be obtained. These variables were analysed non-parametrically.

Thirdly, the possibility that differences in pathogenesis might affect the four neurophysiologically tested systems differently, was studied. Correlations between the tested systems (corrected for differences of age, height, and duration of illness) would indicate variable specific relations between test results, which were different in the two groups. Another approach to this question was to calculate, for each patient, the spread of the deviation from the group mean of seven test results (motor conduction velocity, sensory conduction velocity, SFEMG, autonomic functions) (Table 4). Using this approach, the standardized residuals for each variable in each patient were calculated. The standardized residual is a measure of deviation from the regression line and is expressed as the $\mathrm{SD}$ of the residual around this line. This measure is independent of the scale in which the variable is expressed. The range of the standardized residuals was then determined for each patient by computing the mean absolute deviation of these standardized residuals from the mean value over the variables in each patient.

\section{Results}

We first compared the degree of clinical neurophysiological abnormality in both groups, unadjusted for differences in age, height, and duration of illness (Table 3 ). When a response could not be elicited, the result was interpreted as abnormal. The percentages of unobtainable responses and of abnormal values were similar for both groups (Table 3). Because we found marked intra-individual variation on repeated testing for distal motor latencies, and motor and sensory amplitudes, these values were excluded in the analysis. Only the results of the SFEMG were significantly different for the two groups (chi-square test, $p<0.05$ ). The highest percentages of abnormalities were found for the nerve conduction velocities of the thick myelinated nerves of the lower extremities and for the 


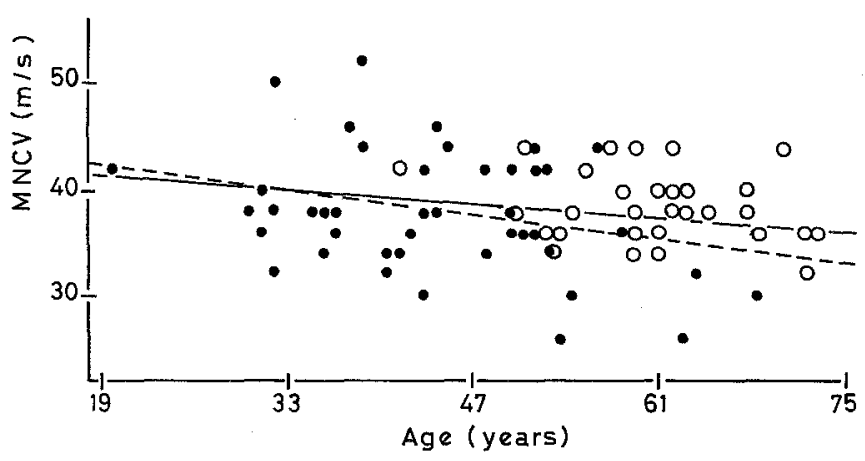

Fig. 1. Regression lines showing the relationship between motor nerve conduction velocity (MNCV) and age within the diabetes groups. Type 1 (insulin-dependent) diabetic patients --.-, Type 2 (non-insulin-dependent) diabetic patients $\mathrm{O}$.. Although the Type 1 diabetic patients were younger than the Type 2 diabetic patients the regression lines were almost parallel

functions of the thin myelinated and unmyelinated autonomic nerves.

Based on the definition of diabetes into Type 1 and 2, one might expect a difference in age and duration of illness (Table 1). No difference in height or sex ratio was found: age, duration of illness, and height were mutually uncorrelated. The influence of these 'background' variables on the values obtained was taken into account by using multiple linear regression analysis. After transforming the variables to normal distributions, the dependence of each variable on age, height, and duration of illness was determined. In some patients no response could be obtained in one or more of the examinations, which was almost certainly related to the existing diabetic polyneuropathy. When no result was obtained, it was assumed to be highly abnormal and was placed at the abnormal end of the distribution for the combined groups by a winsorization procedure [23]. The multiple correlation coefficients for both groups were between 0.40 and 0.60 , except for pupillometry, where the coefficients were below 0.33. Motor and sensory nerve conduction velocities decreased significantly $(p<0.05)$ with increasing height and decreased slightly but not significantly with increasing age. Figure 1 shows the regression lines as an example of the relationship between nerve conduction velocity and age within the two diabetes groups. There was no significant difference between the two groups in the relationship between the three conduction velocities (sural, tibial, ulnar nerve) and height or age. The mean regression coefficient was $-0.14\left(\mathrm{~m} \cdot \mathrm{s}^{-1} \cdot \mathrm{cm}\right.$ height $\left.{ }^{-1}\right)$. A significantly positive relation between fibre density and age was found for the Type 1 group. The latency of the pupil to contract to light (dynamic pupillometry) was found to be only slightly positively related to age in both groups, while in pupil/iris diameter percentage (static pupillometry) no relationship was found between pupil diameter and any one of the background variables.

Except for one comparison, the height dependence of the fibre density ( $t$-test, $0.05>p>0.01)$, differences in regression coefficients for the two diabetic groups were not significant. Therefore, the regression as used in the analysis, was considered to be equal in both groups and age, height, and duration of illness could be used as covariates in an analysis of variance.

The analysis to test the assumption that there might be a difference between the mean values of the results of the eight tests in the Type 1 and the Type 2 group yielded by neither univariate nor multivariate comparison a significant difference in the mean values between the two groups (Table 4).

A different procedure had to be used to analyse the sensory nerve conduction velocities of the sural nerve and the H-M interval values of the H-reflex of the soleus muscle, because of the large number of non-responders. Three classes were formed: class 1 consisted of non-responders, class 2 had values outside the normal range, and class 3 had values within the normal limits. The distribution of the patients over the three classes were similar for both groups. Differences concerning age, duration of illness, and height in the three classes were tested. For sural nerve conduction velocity, the non-responders in the Type 1 group had a longer duration of illness $(p=0.03)$ and were older $(p=0.02)$ than subjects in the two other classes. These differences were not found in the Type 2 group. When analysing the test results of the H-reflex in the three classes, there were no differences concerning age, duration of illness or length in the Type 1 group, whereas in the Type 2 group patients in class 1 were older $(p=0.04)$ and slightly taller $(p=0.08)$ than patients of the two other classes.

No difference in the overall test outcome between the Type 1 and Type 2 groups was found, when differences for age, height, and duration of illness were considered. However, the raw data suggested a difference in nerve fibre involvement and severity of the polyneuropathy. Therefore, the correlation coefficients between the values of the test results were computed among the patients in the two groups separately. Because the dependence of the variables on age, height, or duration of illness enhances the correlation coefficient (a probable artificial increase), the coefficients were corrected for these regressions. The results are shown in Table 5, in which the pairs of variables are arranged according to the type of test variable (motor, sensory, autonomic and terminal branches). Generally, the correlation coefficients in the Type 1 diabetic group were higher than those in the Type 2 diabetic group. When we compared the motor or sensory nerve conduction functions of the arms with those of the legs, we found high and similar correlations in both groups. However, when different systems were compared (motor vs sensory or vs terminal nerve branches) or proximal vs distal nerve conduction functions (H-reflex vs tibial motor nerve conduction functions), the correlation in the Type 1 diabetic group was moderate, while in the Type 2 diabetic group only weak correlations were found. The differences in correlation coefficients between the two groups were not significant.

Another approach was to calculate, for each patient, the spread of the normalized values of the different types of variables tested (for definition see Subjects and methods). When all variables of a patient are about equally normal or abnormal, i.e. the same distance from the regression plane on the background variables, this intra-in- 
Table 5. Correlation for the different variables within the Type 1 (insulin-dependent) and the Type 2 (non-insulin-dependent) diabetes groups

\begin{tabular}{|c|c|c|}
\hline \multirow[b]{2}{*}{ Type of variable } & \multicolumn{2}{|c|}{ Diabetic patients } \\
\hline & Type 1 & Type 2 \\
\hline \multicolumn{3}{|l|}{ Motor vs motor or sensory vs sensory } \\
\hline $\begin{array}{l}\text { MNCV (Ulnar nerve)/ } \\
\text { MNCV (Tibial nerve) } \\
\text { SNCV (Ulnar nerve)/ } \\
\text { SNCV (Sural nerve) }\end{array}$ & $\begin{array}{l}+0.61 \\
+0.70\end{array}$ & $\begin{array}{l}+0.66 \\
+0.60\end{array}$ \\
\hline \multicolumn{3}{|l|}{ Motor vs sensory vs autonomic } \\
\hline $\begin{array}{l}\text { MNCV (Ulnar + Tibial nerve) })^{\mathrm{a}} \\
\text { SNCV (Ulnar nerve) } \\
\text { SNCV (Ulnar nerve)/AUTO (PD \%) } \\
\text { MNCV (Ulnar + Tibial nerve) } / \\
\text { AUTO (PD \%) }\end{array}$ & $\begin{array}{r}+0.41 \\
+0.51 \\
+0.19\end{array}$ & $\begin{array}{l}+0.49 \\
+0.06 \\
-0.06\end{array}$ \\
\hline \multicolumn{3}{|l|}{ Proximal vs distal vs terminal branches } \\
\hline $\begin{array}{l}\text { H-Reflex (Soleus muscle)/ } \\
\text { MNCV (Tibial nerve) } \\
\text { SFEMG (MJ + FD) } \\
\text { MNCV (Ulnar + Tibial nerve) }\end{array}$ & $\begin{array}{l}+0.71 \\
-0.49\end{array}$ & $\begin{array}{l}+0.47 \\
-0.32\end{array}$ \\
\hline
\end{tabular}

${ }^{a}$ The correlation factors of ulnar and Tibial MNCV, MJ and FD were averaged.

MNCV, Motor nerve conduction velocity; SNCV, sensory nerve conduction velocity; AUTO, autonomic nerve function; SFEMG, single fibre electromyography; $\mathrm{PD} \%$, pupil/iris diameter percentage; $\mathrm{MJ}$, mean jitter; FD, fibre density

dividual spread is small. When some variables are clearly abnormal while the other values are within the normal range, the spread is large. This spread is thought to be a measure of distribution of the neuropathological nerve fibre alterations. This spread was computed for all individual patients in each group. A Mann-Whitney U-test did not show any difference between the diabetic groups in this respect $(p>0.8)$. No differences in involvement of particular nerve fibre types or a difference in the manifestation of diabetic polyneuropathy among the individual patients of both groups could be demonstrated.

\section{Discussion}

Although polyneuropathy is a common complication of diabetes mellitus $[2,24]$, no accurate figures on the percentage of diabetic patients with this complication have been recorded. The reported ratios vary from $5 \%$ to $80 \%$ $[9,24,25]$. This variation is partly due to a lack of agreement on diagnostic criteria. In 1988, the American Diabetes Association adopted an operational definition of diabetic peripheral neuropathy and devised a classification system [26]. Of the diabetic neuropathies, peripheral symmetrical mixed sensory-motor-autonomic neuropathy is by far the most common form [1]. Numerous morphological and electrophysiological analyses of human diabetic neuropathy have emphasized entirely different lesions involving peripheral nerve axons, Schwann cells, perineural cells, or endoneurial vascular elements in the pathogenesis of diabetic neuropathy [2-5, 27-34]. However, all these lesions have been described in individuals with advanced chronic polyneuropathy without consider- ation for whether or not the patients had Type 1 and Type 2 diabetes.

Sima and co-workers [6] examined sural nerve biopsies obtained from Type 1 and Type 2 diabetic patients with distal symmetrical polyneuropathy and related these with neurological functions and with control subjects. Their study demonstrates that, despite similarities, there are differences in the histopathology. Despite similar degrees of nerve fibre loss, paranodal swelling and paranodal demyelination, disintegration of the axons with breakdown of its myelin sheath (Wallerian degeneration) was significantly more prevalent in Type 2 diabetes, whereas in Type 1 diabetes axo-glial dysjunction was increased. This morphological difference may reflect a difference in conditioning factors such as an age-related vascular disease or early metabolic disturbance. The prolonged undetected hyperglycaemia, as suspected in Type 2 diabetes, may have a less harmful impact on nerve fibres in comparison with the destructive effects caused by the longer disease duration in Type 1 diabetes.

At a stage of illness when patients have no symptoms of polyneuropathy, one may expect that Type 1 and Type 2 diabetic patients are clinically less different and that there are no advanced histopathological nerve alterations. In the present study it was these patients who were selected in order to gain insight into the early clinical neurophysiological expression of diabetic neuropathy. Polyneuropathy at this stage is not always detected as the signs are often subtle and difficult to assess on routine examination. By measuring different nerve fibre types, it might be possible to determine whether there is a selective or different involvement of particular nerve fibre types in Type 1 and Type 2 diabetic polyneuropathy. We therefore used a broad battery of clinical neurophysiological tests.

Type 1 and Type 2 diabetic patients with a subclinical form of polyneuropathy were selected using psychophysical test methods according to criteria published by Dyck et al. $[9,35]$. We found that the extent of clinical neurophysiological abnormalities was the same in both groups and that it was not possible to differentiate Type 1 diabetic patients from Type 2 diabetic patients on the basis of the number of abnormal results. The results of the neurophysiological tests used did not demonstrate a consistent pattern of abnormalities as there was a predilection for abnormal lower extremity nerve conduction tests and autonomic nerve function tests. The overall clinical neurophysiological findings suggested a far more advanced stage of polyneuropathy than was expected on clinical grounds.

In the present study it was not possible to find support for the assumption that there is a difference in manifestation of polyneuropathy between Type 1 and Type 2 diabetic patients. The clinical neurophysiological picture of diabetic neuropathy tended to be different in Type 2 and Type 1 diabetes. However, when these differences between the groups were statistically tested, they were not significant. The moderate correlations in the Type 1 diabetic group may be the result of a more advanced stage of damage where all nerve fibre types are involved. Another possibility is an aging effect on nerve function. The older Type 2 diabetic patients showed a relatively broad 
range of variable values, resulting in a low correlation between the variables.

In conclusion, the Type 1 and Type 2 diabetic patients in the present study, who all had an asymptomatic form of polyneuropathy, were clinically as well as neurophysiologically indistinguishable. This indicates that although there may be differences in aetiology and pathogenesis leading to an ultimate loss of nerve fibres, in the subclinical stage there is still no selective involvement of particular nerve fibres.

Acknowledgements. The authors gratefully acknowledge Prof. Dr. A.C. van Huffelen and Prof. Dr. D.W.Eekelens for helpful comments on the manuscript. We thank Ms. M.Abels and Ms.H.G.M. Brouwer for their assistance and support in this experiment.

\section{References}

1. Brown MJ, Asbury AK (1984) Diabetic neuropathy. Ann Neurol 15: $2-12$

2. Johnson PC, Doll SC, Cromey DW (1986) Pathogenesis of diabetic neuropathy. Ann Neurol 19:450-457

3. Dyck PJ, Karnes JL, O'Brien P, Okazaki H (1986) The spatial distribution of fiber loss in diabetic polyneuropathy suggests ischemia. Ann Neurol 19: 440-449

4. Dyck PJ, Lais A, Karnes JL, O'Brien P, Rizza R (1986) Fiber loss is primary and multifocal in sural nerves in diabetic polyneuropathy. Ann Neurol 19: 425-439

5. Pirart J (1978) Diabetes mellitus and its degenerative complications: a prospective study of 4,400 patients observed between 1947 and 1973. Diab Care 1: 168-188, 252-263

6. Sima AAF, Nathaniel V, Bril V (1988) Histopathological heterogeneity of neuropathy in IDDM and non-IDDM, and demonstration of axo-glial dysjunction in human diabetic neuropathy. $\mathbf{J}$ Clin Invest 81: 349-364

7. Dyck PJ, Karnes J, Lais EP (1984) Pathologic alteration of the peripheral nervous system of humans. In: Dyck PJ, Thomas PK, Lambert EH (eds) Peripheral neuropathy. Saunders, Philadelphia, pp 760-870

8. Gregersen G (1967) Diabetic neuropathy: influence of age, sex, metabolic control, and duration of diabetes on motor conduction velocity. Neurology 17: 972-980

9. Dyck PJ (1988) Detection, characterization and staging of polyneuropathy: assessed in diabetics. Muscle Nerve 11:21-32

10. Bril V, Sima AAF, Werb MR, Greene DA (1985) Motor electrophysiological studies in diabetic patients. Electro Clin Neurophysiol 61: S147

11. Troni W, Cantello R, Rainero E (1983) The use of the H-reflex in serial evaluation of nerve conduction velocity. Electro Clin Neurophysiol 55: 82-90

12. Shields RW (1987) SFEMG is a sensitive indicator of axonal degeneration in diabetes. Neurology 37: 1394-1397

13. Pfeifer MA, Cook D, Brodsky I (1982) Quantitative evaluation of sympathetic and parasympathetic control of iris function. Diabetes Care 5: 518-528

14. Goldberg JM, Lindblom U (1979) Standardised method of determining vibratory perception thresholds for diagnosis and screening in neurological investigation. J Neurol Neurosurg Psychiatry 42: 793-803

15. Oh SJ (1984) Clinical electromyography: nerve conduction studies. University Park Press, Baltimore, pp 93-113

16. Visser SL, Zonneveldt A, De Rijke W (1983) Normal Hoffmann reflex latencies (H-M interval) in relation to age and body length. Clin Neurol Neurosurg 85: 85-91
17. Trontelj JV, Stålberg E (1986) Axonal stimulation for end-plate studies. J Neurol Neurosurg Psychiatry 49: 677-683

18. Massey JM, Sanders DB (1991) Single-fiber EMG demonstrates reinnervation dynamics after nerve injury. Neurology $41: 1150$ 1151

19. Smith SA, Dewhurst R (1985) A simple diagnostic test for pupillary abnormality in diabetic autonomic neuropathy. Diabetic Med 3: 38-41

20. Reulen JPH, Marcus JT, van Gilst MJ (1988) Stimulation and recording of dynamic pupillary reflex: the IRIS technique. Part 2. Med Biol Eng Comp 26: 27-32

21. de Vos A, Marcus JT, Reulen JPH, Peters HFM, Heimans JJ (1989) The pupillary light reflex in diabetes mellitus: evaluation of a newly developed infrared light reflection method. Diabetes Res 10: 191-195

22. Lanting P, Bos JE, Aartsen J, Schuman L, Reichert-Thoen J, Heimans JJ (1990) Assessment of pupillary light reflex latency and darkness adapted pupil size in control subjects and in diabetic patients with and without cardiovascular autonomic neuropathy. $J$ Neurol Neurosurg Psychiatry 53: 912-914

23. Winer BJ (1962) Statistical principles in experimental design. McGraw-Hill, New York, pp 51-54

24. Thomas PK, Eliasson SG (1984) Diabetic neuropathy. In: Dyck PJ, Thomas PK, Lambert EH, Bunge R (eds) Peripheral neuropathy. Saunders, Philadelphia, pp 1773-1810

25. Boulton AJM, Knight G, Drury J, Ward JD (1985) The prevalence of symptomatic diabetes neuropathy in an insulintreated population. Diabetes Care 8: 125-128

26. American Diabetes Association (1988) Report and recommendations of the San Antonio conference on diabetic neuropathy. Diabetes Care 11: 592-597

27. Williams E, Timperley WR, Ward JD, Duckworth T (1980) Electron microscopic studies of vessels in diabetic peripheral neuropathy. J Clin Pathol 33: 462-470

28. Sima AAF, Brismar T (1985) Reversible diabetic nerve dysfunction: structural correlates to electrophysiological abnormalities. Ann Neurol 18:21-29

29. Vracko R (1982) A comparison of microvascular lesions in diabetes mellitus with those of normal aging. J Am Geriatr Soc 30: 201-205

30. Dyck PJ, Sherman WR, Hallcher LM, Service FJ, O'Brien PC (1980) Human diabetic endoneurial sorbitol, fructose and myoinositol related to sural nerve morphometry. Ann Neurol 8: 590596

31. Dyck PJ, Hansen S, Karnes J (1985) Capillary number and percentage closed in human diabetic sural nerve. Proc Natl Acad Sci USA 82: 2513-2517

32. Chopra JS, Fannin T (1971) Pathology of diabetic neuropathy. J Pathol Bacteriol 104: 175-184

33. Behse F, Buchtal F, Carlsen F (1977) Nerve biopsy and conduction studies in diabetic neuropathy. J Neurol Neurosurg Psychiatry 40: 1072-1082

34. Kimura J, Yamada T, Stevland NP (1979) Distal slowing of motor nerve conduction velocity in diabetic polyneuropathy. J Neurol Sci 42: 291-302

35. Dyck PJ, Karnes JL, Daube J (1985) Clinical and neuropathological criteria for the diagnosis and staging of diabetic polyneuropathy. Brain 108: 861-880

Received: 5 December 1991

and in final revised form: 2 April 1992

Dr.P.L.Oey

Department of Clinical Neurophysiology

University Hospital Utrecht

Heidelberglaan 100

NL-3584 CX Utrecht

The Netherlands 